\title{
UNILATERAL LUNG TRANSRADIANCY
}

BY

\author{
LYNNE REID AND GEORGE SIMON \\ From the Institute of Diseases of the Chest and the Brompton Hospital, London
}

(RECEIVED FCR PUBLICATION JANUARY 23, 1962)

The distinctive radiological picture of unilateral transradiancy without collapse (Figs. 1 and 2) has been increasingly recognized in the last decade, but no detailed pathological description has emerged and the cause and pathogenesis have been uncertain. In 1954 Macleod described nine cases of unilateral transradiancy and found that the affected lung was either small or normal in size and that there was no evidence of bronchial obstruction. He excluded from his series those with the additional radiological evidence of old primary tuberculous infection and he commented that the condition was of 'an undetermined pathology.' A case of transradiancy of the right

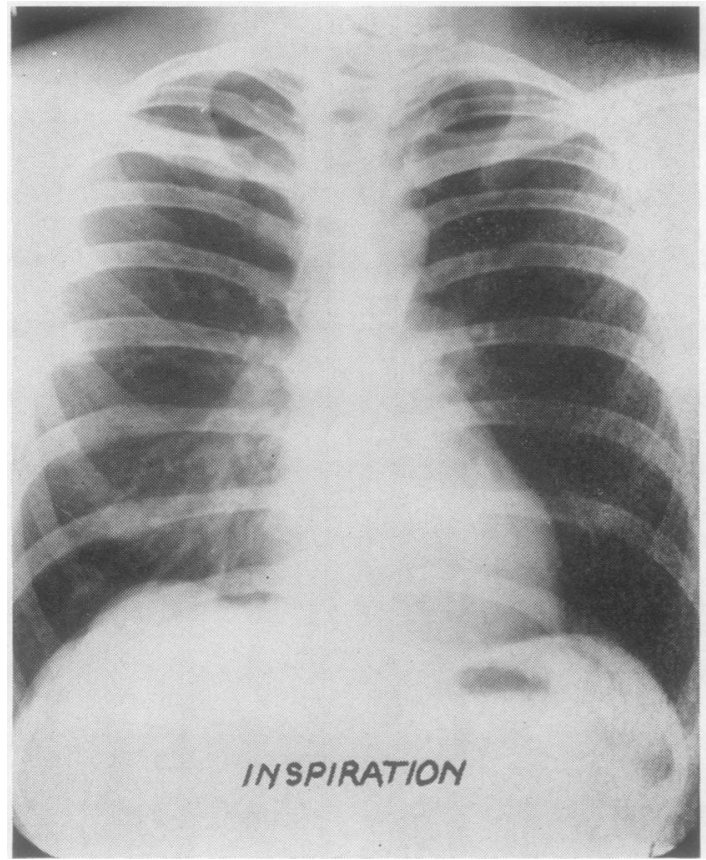

Fio. 1 lung in a child of 6 years had been reported by Swyer and James in 1953. Angiography showed a reduction in size of the pulmonary artery on the affected side, although at operation the surgeon reported that the right pulmonary artery was larger than was expected from the angiogram. Resection was carried out because the child had suffered from recurrent pulmonary infections from the age of 5 weeks, which affected mainly the right lung. Radiographic evidence that the pulmonary artery was small and the lung reduced in volume, as shown by displacement of the heart to the right, suggested a functional deficiency. Carbon was present only on the anterior part of 
the right upper lobe and a group of cystic spaces was found in the apex. Microscopically, evidence of bronchitis, bronchiolitis, and emphysematous alveoli was found.

Under the title "Unilateral "emphysema'," Dornhorst, Heaf, and Semple (1957) reported three cases, including one in which narrowing of the main bronchus on the affected side had been noted at bronchoscopy several years earlier. Macleod excluded cases in which narrowing was present. Examination of respiratory function was carried out on two of their subjects and in neither did administration of gas under positive pressure increase ventilation on the abnormal side when the normal was occluded. They inflated the lung by pressure on the spirometer bell and found an increase in airway resistance and a slowing of passive deflation. Fluoroscopy during bronchography did not show collapse of the walls of the central bronchi, though such a mechanism for trapping would not have been a hindrance to positive pressure inflation. Arterial oxygen and carbon dioxide tensions were normal, both at rest and on exercise. In the first case the abnormal lung was responsible for only $10 \%$ of the ventilation and $5 \%$ of the oxygen uptake, and the maximum breathing capacity was reduced to 79 litres per minute (normal 111-164).

Rivett (1960) reported two cases of right-sided and one of left-sided transradiancy. In one of the former a calcified gland was seen at the left hilum (that is, of the opposite lung), and the main lobar and segmental arteries (the contralateral ones) were enlarged. In this respect this case is unique. Furthermore, unlike previously reported cases, there was deterioration in the patient's general condition.

In a paper on "Hypoplasia of the pulmonary arteries," Belcher, Capel, Pattinson, and Smart (1959) described four cases of unilateral transradiancy, resemb'ing in their fluoroscopic and bronchographic features the cases reported above, together with 13 of lobar transradiancy (nine in the recent and four in a previous paper (Belcher and Pattinson, 1957) ) which they placed in the same clinical and radiological category as that described by Macleod. From angiograms in two of the four cases, measurements of the main pulmonary arteries on the involved side were found to be 20 and $14 \mathrm{~mm}$. compared with 34 and $36 \mathrm{~mm}$. on the normal side. These authors argue that the transradiancy is the result of hypoplasia of the pulmonary artery. In the earlier paper Belcher and Pattinson considered that the hypoplasia was probably congenital and they still favour this explanation although 'the possibility that the lesion is entirely acquired cannot be excluded.'

Recent cases of unilateral transradiancy have been reported by Katz and Wagner (1959), by Margolin, Rosenberg, Felson, and Baum (1959), by Fouché, Spears, and Ogilvie (1960), by Darke, Chrispin, and Snowden (1960), by Dyson, HughJones, Newbery, Sinclair, and West (1960), by Francis (1961), and by Leahy (1961). These authors give results of additional tests of respiratory function, confirming that the affected lung hardly contributes to oxygen uptake and ventilation, that in it air is trapped, and that practically no pulmonary artery blood flows through it.

All authors appear uncertain as to whether the condition is congenital, developmental, or acquired; nor are they unanimous regarding the significance of the small pulmonary artery associated with the abnormal lung, whether it is the cause of both the alveolar and bronchial deficiency or the result of the latter.

The purpose of this paper is to present bronchographic and pathological evidence showing that the condition may arise from disease in childhood which damages the peripheral part of the bronchial tree. The bronchographic evidence is derived from a study of the appearances in the published cases together with those in 12 new ones, and the pathological evidence from examination of three operation specimens.

\section{BRonchographic FEATURES}

Assessment of Illustrations in Previously REPORTED CASES.-None of the authors of previous papers concluded that there were specific bronchographic changes related to the unilateral transradiancy shown in the plain radiograph, but all their published illustrations are found on our assessment to show such changes.

In a normal bronchogram the contrast medium is usually conducted to the smaller bronchi and bronchioli (see Fig. 5, opposite black arrow) where it produces the 'centimetre' pattern, so named because the branches at this point are more regular than at more proximal levels and lie roughly $1 \mathrm{~cm}$. apart (Reid and Simon, 1958). More distally, within the secondary lobule itself, the branches arise a few millimetres apart; they are a few millimetres long and, when filled, produce the 'millimetre' pattern representing terminal or near-terminal bronchioli. This pattern also may be seen in a normal bronchogram.

In none of the bronchograms under review does filling in the transradiant lung reach a peripheral 
level, which indicates a failure of normal conduction. This evidence of abnormality is often overlooked, being perhaps ascribed to a technical fault such as too little contrast medium or too little time for it to flow distally; more often the cause is a pathological condition. In some cases there is an excess of mucus either blocking the further onward passage of the contrast medium or hindering the normal inspiratory 'suck' which is the most important factor in the conduction of the contrast medium to the smaller peripheral bronchi.

The inspiratory suck will also be poor if there is airway obstruction from organic occlusion of small peripheral bronchi or bronchioli, a change found in the three resected specimens. These occlusions may be associated with air trapping, distal emphysema, and bullae, which will themselves hinder the respiratory suck in nearby branches.

An organic occlusion can be presumed if the contrast medium outline shows a bronchus that ends in an irregular tapering fashion, in a bulbous expansion, or in a small circular ' pool.' Such end irregularities are frequent in many of the published illustrations.

NEw CASES.-We have studied 12 further cases of unilateral transradiancy, and in none of these is there a completely normal bronchographic pattern.

In five there is a certain amount of peripheral filling: one filled throughout the lung, though most of the branches ended in small dilatations or pools; in three others only a few branches in one lobe filled; and in the fifth only a single basal branch filled (see Fig. 5), the other branches in this and in the three previous cases filling only to a 'middle level,' that is, as far as the eighth to tenth generation along an axial pathway. In another five of the 12 cases filling did not reach further than the middle level in any branches (see Fig. 6), and in the remaining two cases never further than the first four generations, that is a 'proximal level' (see Fig. 7).

In all 12 cases there are abnormal endings to the shadow of the contrast medium, in nine a mixture of 'broken bough' appearance and distortion (see Fig. 7), and in three irregularities of all the endings. Details are given in Table I.

In contrast to the transradiant side, the contralateral side shows peripheral filling at least as far as the 'centimetre pattern' in the five cases in which bronchograms of both sides were available. Filling extended to a more peripheral level in all branches and in addition there were no abnormal endings to the contrast medium shadow. Other radiographic findings in the transradiant side were a small or normal sized lung, and a small pulmonary artery with small lung vessels, the small size of the pulmonary artery being confirmed in angiograms in several cases (see Fig. 4). The diaphragm was low and flat in five of the 12 cases, while the amount of flattening or depression varied. Some showed restriction of movement relative to the other side. In those cases observed fluoroscopically or in radiographs taken during expiration, the heart and trachea tended on expiration to be displaced towards the normal side (Figs. 1 and 2).

In one of the 12 patients (Case 9) we ascribe the unilateral transradiancy to childhood tuberculosis at the age of 6 , and from a series of bronchograms over many years the effect of growth on the abnormal bronchial tree can be traced.

The child was admitted to hospital because of fever. His Mantoux was positive to a 1 in 10,000 dilution.

TABLE I

SUMMARY OF BRONCHOGRAPHIC ABNORMALITIES IN 12 NEW CASES

\begin{tabular}{|c|c|c|c|c|c|c|c|}
\hline \multirow{2}{*}{$\begin{array}{l}\text { Case } \\
\text { No. }\end{array}$} & & \multirow[b]{2}{*}{ Sex } & \multirow[b]{2}{*}{ Age } & \multirow[b]{2}{*}{ Side } & \multicolumn{2}{|c|}{ Degree of Filling } & \multirow{2}{*}{$\begin{array}{l}\text { Comment } \\
\text { on Bronchogram }\end{array}$} \\
\hline & & & & & Maximum & Average & \\
\hline$* 1$ & J.H. & $\mathbf{M}$ & 55 & $\mathbf{L}$ & Middle & Middle & Broken bough and distorted ends; dilatation \\
\hline$* 3$ & $\begin{array}{l}\text { J.D. } \\
\text { G.C. } \\
\text { M.Y. }\end{array}$ & $\begin{array}{l}\mathbf{M} \\
\mathbf{M} \\
\mathbf{M}\end{array}$ & $\begin{array}{l}43 \\
54 \\
21\end{array}$ & $\begin{array}{l}\mathbf{L} \\
\mathbf{L} \\
\mathbf{L}\end{array}$ & $\begin{array}{l}\text { Përipheral } \\
\text { Middle }\end{array}$ & $\begin{array}{l}, \\
,\end{array}$ & $\begin{array}{lll}, & \text {, } & \text { endings; dilated mucous gland ducts } \\
, & , & \text { with occasional tapering end } \\
,, & , & \text { and' distorted ends }\end{array}$ \\
\hline 5 & M.K. & $\mathbf{M}$ & 45 & $\mathbf{R}$ & $\begin{array}{l}\text { "Cm. pattern" } \\
\text { one branch only }\end{array}$ &, & pools $, \quad, \quad, \quad, \quad$, some dilatation and \\
\hline 6 & E.D. & $\mathbf{M}$ & 41 & $\mathbf{L}$ & $\begin{array}{l}\text { Peripheral } \\
\text { (V.L.) }\end{array}$ & ,, (L.L.) & Distorted ends and dilatation \\
\hline 7 & L.D. & $\mathbf{F}$ & 53 & $\mathbf{L}$ & $\begin{array}{l}\text { One area } \\
\text { normal }\end{array}$ & Middle & Broken bough and distorted ends \\
\hline 8 & M.C. & $\mathbf{M}$ & 58 & $\underset{\mathbf{R}}{\mathbf{R}}$ & $\begin{array}{l}\text { Peripheral } \\
\text { Proximal }\end{array}$ & $\begin{array}{l}\text { Peripheral } \\
\text { Proximal }\end{array}$ & $\begin{array}{l}\text { Distorted ends; pools }++ \\
\text { Broken bough and distorted ends; some dilatation }\end{array}$ \\
\hline 10 & J.D. & $\mathbf{F}$ & 12 & $\mathbf{L}$ & Peripheral & Middle & occasionäl bronchus $\quad, \quad, \quad$ slight dilatation \\
\hline $\begin{array}{l}11 \\
12\end{array}$ & $\begin{array}{l}\text { M.E. } \\
\text { A.N. }\end{array}$ & $\begin{array}{l}\mathbf{F} \\
\mathbf{M}\end{array}$ & $\begin{array}{l}47 \\
46\end{array}$ & $\begin{array}{l}\mathbf{L} \\
\mathbf{L}\end{array}$ & $\begin{array}{l}\text { Middle } \\
,,\end{array}$ & Proximal & $\begin{array}{l}\text { Distorted ends; pools } \\
\text { Broken bough and distorted ends; pools }++ \text { and } \\
\text { dilatation }++\end{array}$ \\
\hline
\end{tabular}


He developed a left spontaneous pneumothorax and the left lower lobe was found to be collapsed. At bronchoscopy the left main bronchus was full of pus. On one occasion four colonies of tubercle bacilli were grown from pulmonary secretion, which confirmed the diagnosis of pulmonary tuberculosis.

Radiographs over a number of years showed a progression from consolidation and collapse of the lower lobe to re-aeration. The initial radiograph showed collapse of the left lower lobe but not abnormal transradiancy of the left upper lobe ; films taken two years later, after re-expansion, showed an increased transradiancy of the whole of the left lung, which has persisted. The bronchogram taken at the age of 7 showed good peripheral filling in the right lung, but in the left no normal peripheral filling was seen (Fig. 7), and although the upper lobe showed mainly a broken bough appearance, in the lower lobe dilatation and irregular tapering endings were evident.

The bronchogram was repeated at 12 and 22 years of age and these showed that the level of the blockages in the bronchial tree remained unchanged although the length between certain bronchial landmarks had increased. Between two points on the upper part of the left main bronchus, identifiable in the bronchograms taken at the ages of 7,12 , and 22 , the length had increased from 9 to 11.5 to $14 \mathrm{~cm}$. The chest length, measuring between the first rib and the diaphragm, was 18,23 , and $29 \mathrm{~cm}$. respectively, and the supra and infra-hilar regions were increased in the same proportion. The diameter of the left main bronchus had increased from 1.3 to $2 \mathrm{~cm}$. between the ages of 12 and 22 years.

As in case 1, the transradiancy and general appearance in the plain radiographs have remained unchanged to the present time, that is, for 15 years. This seems to have been so in all cases where the ac was a long follow-up, including Macleod's cases followed up by Dornhorst et al. (1957).

\section{Pathological Features}

The pathological material was taken from three patients with unilateral transradiancy in whom resection was performed. In cases 1 and 2 the whole of the left lung was removed. The patients complained of breathlessness, and since it was found that the affected lung was contributing little to respiration, it was thought that the trapping of air in it, with consequent displacement of the heart towards the normal side on expiration, was an embarrassment to the normal lung. In case 3 the patient had a haemoptysis which it was thought came from the basal segments or lingula, which in the bronchograms showed the most irregular tapering ends as well as slight dilatation. While the specimens are described in detail, brief details of the clinical features of these cases are given as they resemble others reported in the literature.
CASE 1.-J.H., a man, was first radiographed for routine purposes at the age of 40 when he was asymptomatic. Left-sided transradiancy was seen which remained unchanged until the time of operation. He had had a severe chest illness when 7 years of age. Nine years after the first radiograph he began to notice shortness of breath, but he could walk a long distance at his own speed. There was some cough and sputum at this time. Breath sounds were reduced on the left. The radiograph showed left-sided transradiancy; the left pulmonary artery and its branches were small. There was marked displacement of the heart to the right at the end of forced expiration. The left bronchogram showed that filling was limited to the 'middle level' (Fig. 6). The inferior division of the lingular pathway showed a narrow tapering end which was sectioned (Fig. 9). The other bronchi showed slight dilatation and, for the most part, tapering endings. An angiogram showed a small left pulmonary artery and poor filling of its branches (Fig. 4) with normal filling on the right side. Respiratory function studies showed very little ventilation of the left lung.

Macroscopic Appearance of the Left Lung.Carbon was irregularly distributed throughout the lung. On the pleural surface carbon was particularly heavy over the medial and posterior parts of the upper lobe and over the apical lower lobe, but the anterior part of the lower lobe and the lingula were striking because of a pinkness suggesting absence of carbon. The whole was aerated; thus, the presence of carbon indicated that the air had arrived directly by the proper bronchial routes, and its absence that there had been collateral drift from neighbouring segments. In other words, where the ventilation to the region was poor, little carbon was brought in. The surgeon described the lung when removed as fluffy and light in texture.

Measurements were made on the lower lobe bronchus, and the wall thickness was found to be $3 \mathrm{~mm}$. ( 2 to $2.5 \mathrm{~mm}$. being usual) and the internal measurements of two cross-section diameters, 13 and $8 \mathrm{~mm}$., which is probably on the low side for an adult man. Lobar bronchi of adult men normally show variability in size and wall thickness.

The diameter of the left pulmonary artery was smaller than that of the normal adult, being $12 \mathrm{~mm}$. when flattened.

Branches of the pulmonary artery were injected with radio-opaque solution by hand from a syringe. The radiograph showed that the complete complement of segmental branches was present. The pulmonary artery showed no localized narrowing and the peripheral branches were widely patent and filled to within the lobules and even acini, although there were considerably fewer fine peripheral branches than in a normal specimen. Comparison at the peripheral level is difficult when segments are injected separately by hand. There was cross-filling between the bronchial arteries of several large bronchi and the 


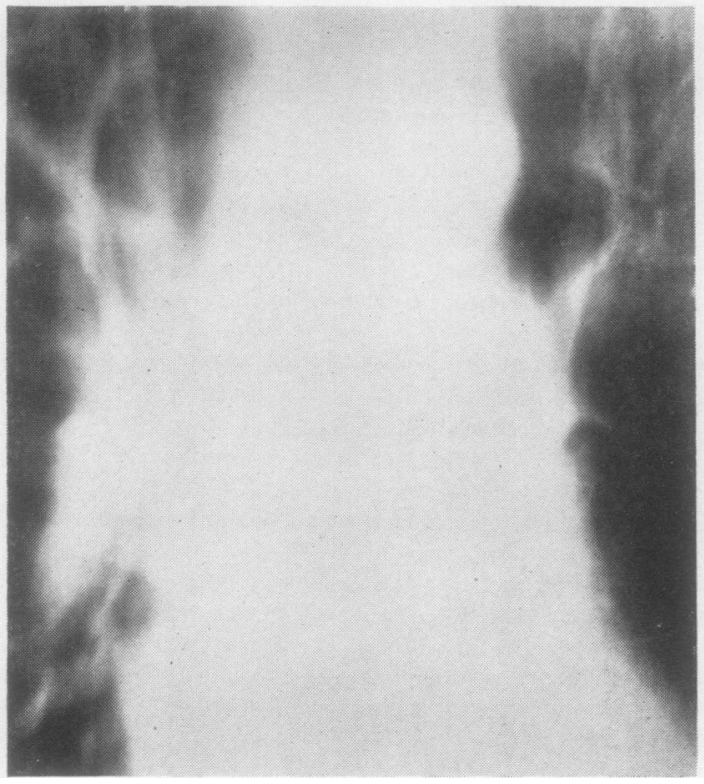

Fig. 3.-Case 6. Tomogram shows small size of the left pulmonary artery together with its intrapulmonary branches.

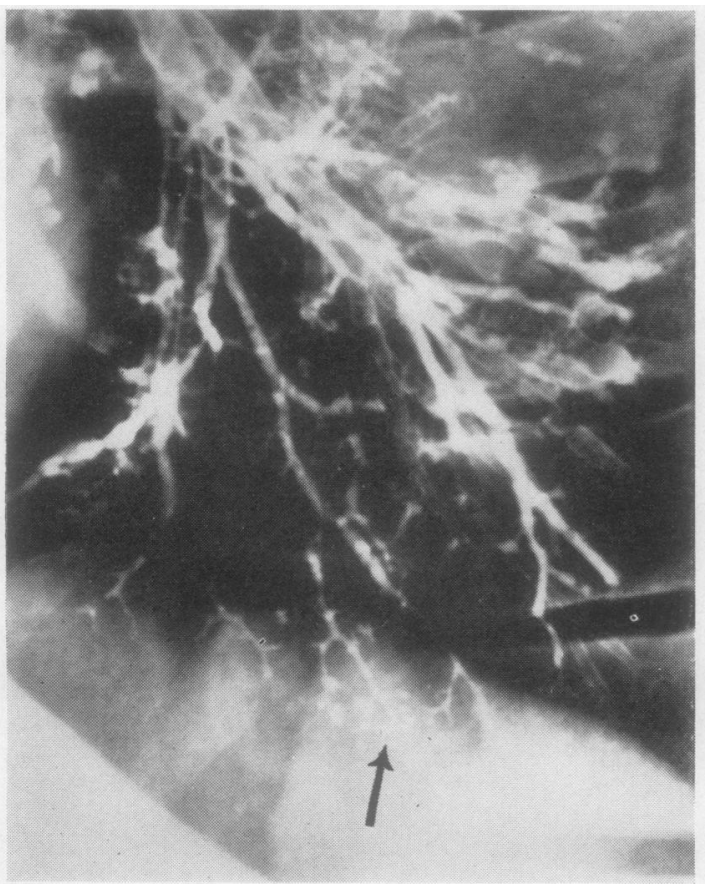

Fig. 5.-Case 3. Bronchogram shows good peripheral filling in one branch only seen as fine lines in the original (opposite arrow); others show some broken bough ends and some which are irregular and tapering, indicating organic occlusions.

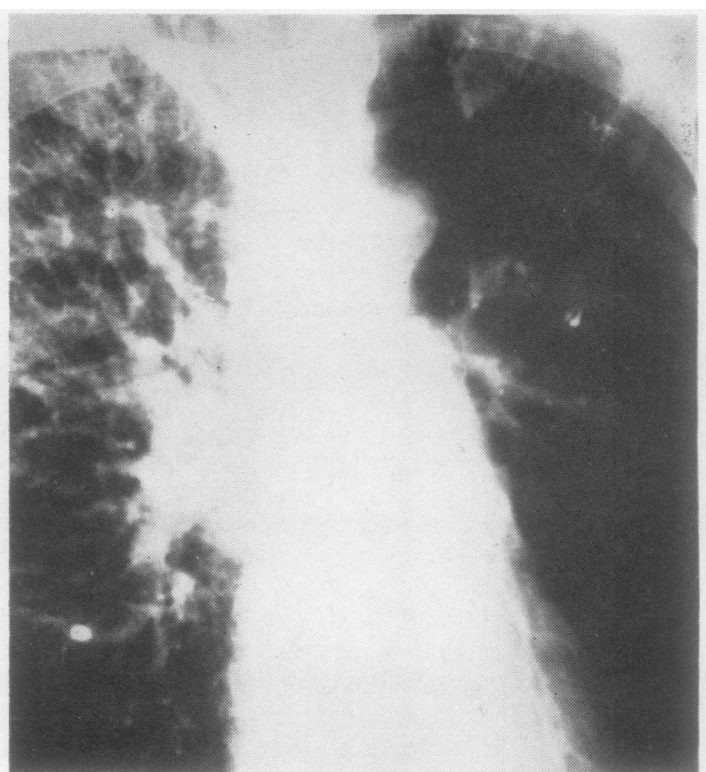

FIG. 4.-Case 1. Angiogram shows similar features to Fig. 3 with great reduction in the peripheral vascular pattern.
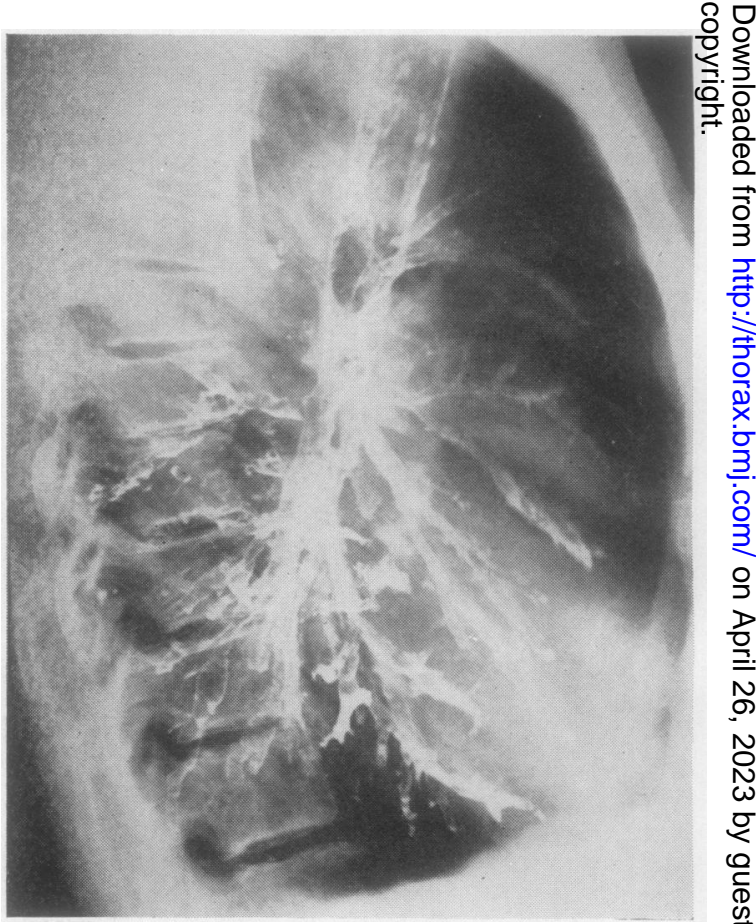

Fig. 6.-Case 1. Left bronchogram showing fuilure to fill peripheral bronchi with dilatation of many filled pathways, such as is seen in other cases illustrated in the literature. Tapering and irregular endings are seen. 


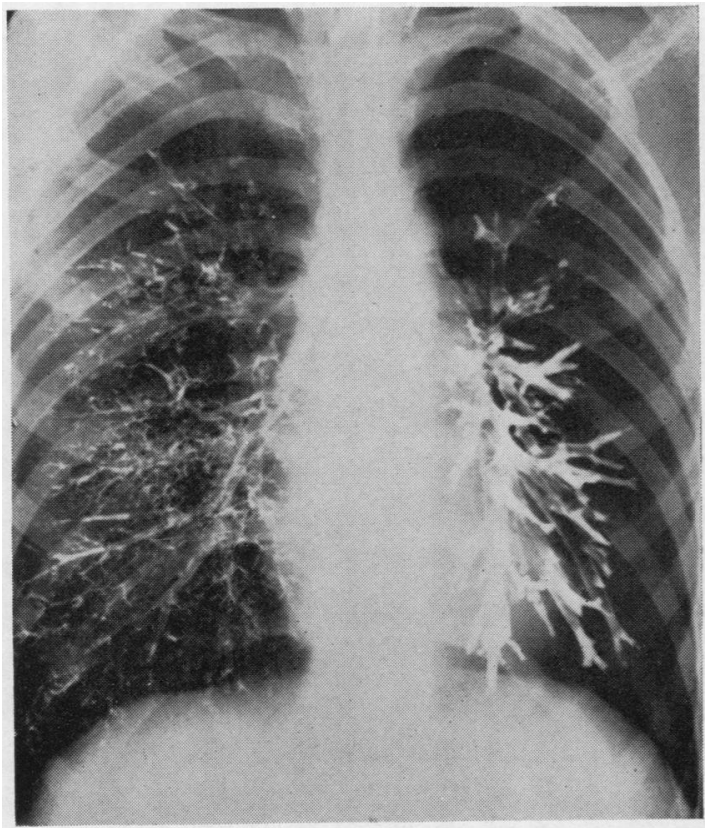

Fig. 7

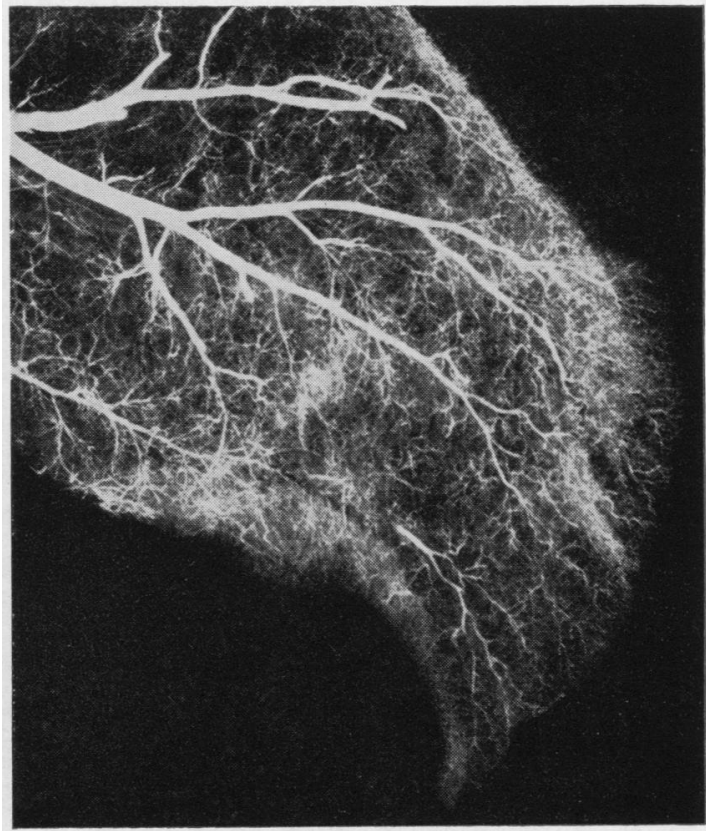

FIG. 8

Fig. 7.-Case 9. Bronchogram in which comparison of the normal with the affected lung can be made. Filling in the left lung stops at approximately the same level in all pathways. Most of the endings of the filled bronchi are squared, suggesting that the level at which filling ceased is not necessarily a point of organic obliteration.

FIG. 8.-Case 2. Pulmonary artery injection with barium-gelatin mixture shows slice of lower part of left upper lobe with large branches narrowed and fine peripheral filling but fewer intra-acinar branches than normal.

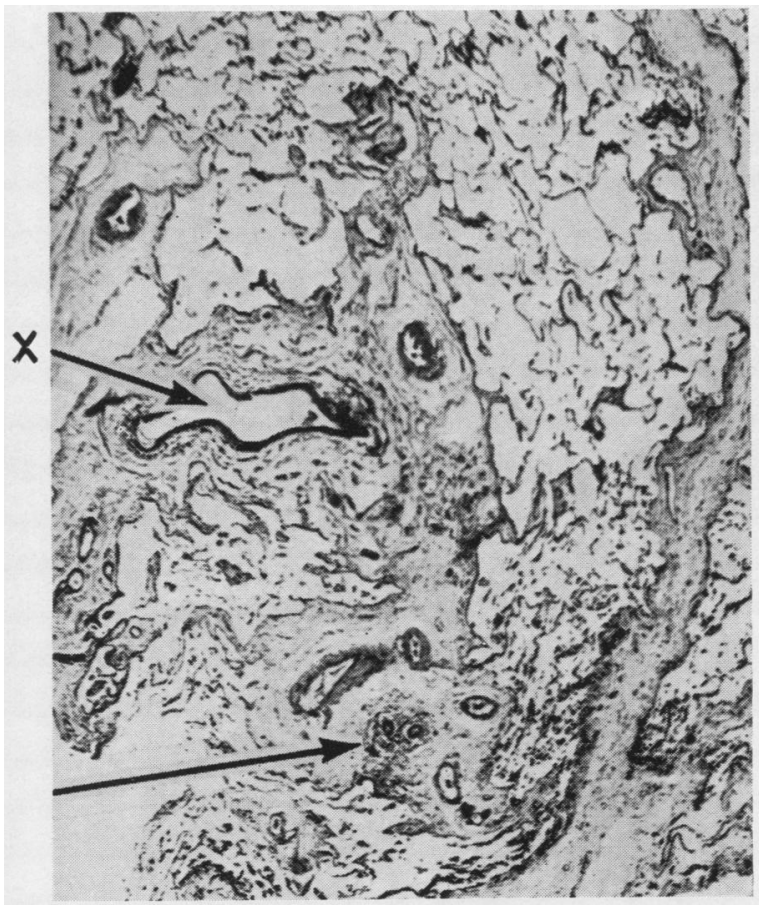

Fig. 9

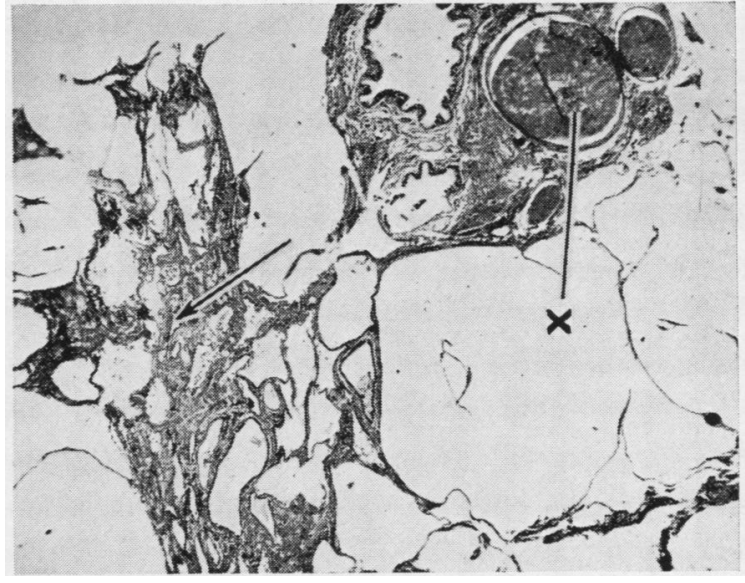

FIG. 10

Fig. 9.-Case 1. Photomicrograph shows area from tip of lingula. Bronchiolitis obliterans is seen in area marked by arrow; $\mathrm{X}=$ patent lingular pathway. Alveoli show mild emphysema in upper half.

FIG. 10.-Case of unilateral transradiancy with collapsed middle lobe, but lower lobe shows obliterative bronchiolitis and not just compensatory emphysema. Photomicrograph shous emphyscmatous lung around foci of obliterative bronchiolar scarring marked by arrow. Pulmonary artery (X) shows injection so!ution in its lumen with patent bronchus to the left. 
pulmonary artery branches, which is not found in the normal lung.

Dissection of Bronchi.-The proximal pathways were patent. An inferior lingular pathway was chosen for examination as it was representative and easy to identify in both the bronchogram and the specimen. Counting along this pathway, dilatation was evident between the fifth and tenth generations and thereafter macroscopic dissection became impossible, the bronchus being obliterated. In the normal lung it is usually possible to dissect as many as 15 , or even 20, bronchial generations along a lingular pathway with naked-eye examination. The obliterated bronchus lay closer to the pleura than would a tenth generation bronchus in a normal lung. The tissue lying beyond the limit of macroscopic dissection was included in a block for section and from it serial sections were taken.

Microscopic Examination of the Bronchi.-The obliteration of the inferior lingular bronchus was confirmed microscopically. The peripheral airways were condensed into a centimetre or so, and extra generations were counted, bringing the total to 19 along the lingular axial pathway, taking each lateral scar with its bronchiolar remnants as one branch. It is possible that a single scar might be the remains of more than one bronchiolus, so that this count could be low. Both main and side branches were thus distorted and irregular, and most of them were the site of numerous obliterative lesions (Fig. 9). Areas of scarring involving bronchiolar walls and lumen, such as were seen in the lingula, were not present in all sections. Measurement of the mucous gland layer in the wall of the main bronchus showed it to be hypertrophied (Reid, 1960). The thickness was within the range found in patients with chronic bronchitis, and it is probable that during the previous seven years, when this patient had developed a persistently productive cough, the diagnosis of chronic bronchitis would have been justified. As the unilateral transradiancy had been known to be present for more than 15 years, we believe that chronic bronchitis had nothing to do with its development. In other cases of this disorder increase in the gland measurement has not been found, which suggests that in this case gland hypertrophy was distinct from the peripheral changes.

The Alveoli.-In blocks of tissue selected from deep down in both lobes as well as from the subpleural region, emphysematous alveoli were found which contained much pigment, unlike the sections from the lingula, which were free of it.

The Pulmonary Artery. - The walls of the pulmonary artery were of normal structure but somewhat hypoplastic; they were well distended with no evidence of hypertrophy of the media such as might occur in pulmonary hypertension. In the peripheral part of the lung also the walls of the pulmonary artery branches seemed rather narrow. The branches filled well within acini and even at the periphery, although there was clearly great loss of alveolar wall area and capillary bed: no evidence of endarteritis or organization of thrombi was seen.

In summary, this lung showed emphysema with patchy bronchiolitis obliterans; injection of the pulmonary artery showed that, although it was hypoplastic, it branched normally and was patent to within the acini where the capillary area was less than in the normal lung.

CASE 2.-J.H. D., a man aged 43, first presented during an attack of pneumonia when he admitted that he had been short of breath and wheezing for about 20 years. A radiograph showed increased transradiancy of the left lung and at bronchoscopy it was seen that the left main bronchus was of a smaller calibre than the right, but no other abnormality was observed. Three years later he again attended hospital because, following a cold, he was more short of breath. He produced only a trace of mucoid sputum in 24 hours. At the age of 6 he had had tuberculosis of the left tibia, left arm, and cervical lymph nodes: at 8 years he was 'very ill with pneumonia.' He had worked as a boiler coverer with asbestos for 33 years and smoked 20 to 25 cigarettes a day.

Breath sounds over the left chest were difficult to hear. A chest radiograph showed that the diaphragm was flat with a poor range of movement, $1.5 \mathrm{~cm}$. on the left and $2.5 \mathrm{~cm}$. on the right. The left hilar vessels were smaller than the right and the left midō lung vessels were very small: angiography confirmed this and showed hardly any flow on the left. Fluoroscopy showed increased transradiancy of the left lung on expiration with a shift of the heart to the right. Bronchography on the left side showed filling only to the fifth generation, that is, the middle region. The endings were of the broken bough type and residues of contrast medium were evident in some peripheral parts in one or two regions next day. Parts of the right lung had filled as far as the ' millimetre pattern.'

Respiratory function studies showed that the vital capacity was $1,910 \mathrm{ml}$. and the forced expiratory volume (1 second) was $700 \mathrm{ml}$. or $37 \%$ of the vital capacity: bronchospirometry indicated that the right lung was responsible for most of the ventilation $(68 \%$ of total) and practically all of the oxygen uptake ( 90 to $100 \%$ of total). Resection of the left lung was advised.

At operation the surgeon noted that the lung felt light, was pale and not increased in size but was difficult to deflate. A lymph node found between the bronchus and the pulmonary artery was thought to be the possible site of previous tuberculous infection because of its adherence to the bronchial wall; it was not removed. The diameter of the pulmonary artery was $2 \mathrm{~cm}$.

Macroscopic Appearance of the Left Lung.-Less carbon was present in the lower lobe and lingula than in the apical region. Several large scars were present under the pleura. Injection of the pulmonary arteries 
by syringe with radio-opaque material revealed that its branches were mostly well filled to a peripheral level (Fig. 8) and also that bronchial arteries in the scars had filled and that these passed back to the hilum. The intra-segmental pulmonary arteries were narrower than normal, but with no constrictions or irregularities. In some areas side branches were fewer. On naked-eye examination of the cut surface a few large scars were apparent. The lung was emphysematous, but no bullae were seen. Dissection of the bronchial tree showed that while peripheral stenosis and scarring was present, this was less evident than in case 1 . The left main bronchus was $12 \times 9 \mathrm{~mm}$. internal diameter in the fixed specimen with a wall about $2 \mathrm{~mm}$. thick.

Microscopic Examination of the Left Lung.-Blocks of tissue were taken for section from six regions of the lung periphery as well as from three hilar bronchi and the accompanying pulmonary artery. Microscopically the main bronchi showed no evidence of gland hypertrophy such as occurs in patients who have chronic bronchitis. The bronchioli showed fibrosis, distortion, and stenosis which was not evident macroscopically. Large, ragged alveoli, indicating pathological emphysema, were demonstrated. The pulmonary artery branches running with the diseased bronchioli filled with injection material quite satisfactorily. Scars in the apical region of the upper lobe and the apical segment of the lower lobe included numerous bronchioli. As a result of the pulmonary artery injection small bronchial arterial branches both within and not contained in scars had filled.

In summary, this lung showed widespread emphysema and also several large peripheral scars; in addition many bronchioli were stenosed and others showed an increase of fibrous tissue in their wall, indicating old inflammation. The pulmonary arteries within the lung were narrower than normal but patent, with no evidence of thrombosis or endarteritis.

CASE 3.-G.C., a man aged 54, presented with a haemoptysis to the extent of one cupful ; this was his only symptom. The radiograph showed left-sided transradiancy with the pulmonary artery and its branches small; tomography confirmed these findings (as in Fig. 3). The diaphragm on the left was low and flat and the lung reduced in size. In the left bronchogram (Fig. 5) one branch in the lower lobe filled to the periphery but, for the most part, the contrast medium only reached to the mid-region; in the lingula and apical lower lobe, tapering endings and dilatations, indicating organic occlusions, were also present. On the right there was good peripheral filling. Bronchospirometry showed that the left lung took up $18 \%$ of the total oxygen, although a somewhat higher percentage of ventilation went to this lung. A year later, after two further haemoptyses each of about half a pint, the basal segments of the left lower lobe and the lingula were removed as a bronchogram showed these to be the most diseased parts.
Lingula and Basal Segments of Left Lung.-At resection the external diameter of the pulmonary artery distal to the ligamentum arteriosum was $2 \mathrm{~cm}$. and the bronchial vessels to the lung were enlarged to a diameter of 2 or $3 \mathrm{~mm}$., thus resembling radial arteries. Coal pigment was irregularly distributed over the basal segments but the diaphragmatic surface was almost free of it. The two cut ends of the pulmonary arterial branches to the basal segments were injected with radio-opaque solution. Fine pleural filling occurred over the basal segments, particularly over the diaphragmatic surface and in the medial and anterior region. The bronchial artery had filled from the pulmonary artery through precapillary vessels. On cutting, the lung was found to be fluffy in consistency, especially distally and medially. The bronchial tree could not be dissected as far distally as usual and obliteration of the bronchial tree was apparent on naked-eye examination, notably in the medial and diaphragmatic region of the lobe. The lingula was large and solid with blood which had probably been aspirated pre-operatively. In its proximal parts, bronchiolar and bronchial thickening and scarring were present.

Microscopic examination confirmed both emphysema and bronchiolar scarring (as Fig. 10), with distortion and obliteration in some areas and no evidence of gland hypertrophy. A feature of the sections was the filling of bronchial arterioles from the pulmonary artery; the systemic hypertension $(190 / 120 \mathrm{~mm}$. $\mathrm{Hg})$ of the patient may have been the explanation for this.

\section{Discussion}

This type of pulmonary unilateral transradiancy is accompanied by three abnormalities, distortion and occlusion of bronchi and bronchioli, hypoplasia of the pulmonary tissue and pulmonary artery and its branches, and emphysema.

Distortion AND OCClusion OF BRonchi AND BRONCHIOLI.- In the bronchograms of all cases and in the three lungs examined after resection there was obliterative disease of many bronchi and bronchioli. The lesions in the three cases were irregular in distribution and there appeared to be enough normal pathways patent to maintain ventilation to the lung as a whole, even if largely by collateral air-drift. There was variation in the severity of the lesions, which ranged from submucous fibrosis in the wall of the bronchial tree to irregularity of the lumen and, in many airways, to occlusion. Bronchographically, normal pathways, distorted bronchi, and occluded airways were found, often in proximity to each other; completely filled normal airways were exceptional. Lesions were found at various levels between the fourth bronchial generation and the terminal bronchioli. 
The counts of bronchial generations traced along an axial pathway, including the region beyond the occlusion, were normal, in contrast to those found in the hypoplastic lung of patients with congenital diaphragmatic hernia, in which condition fewer generations were found (Areechon and Reid, 1962). This, together with the fibrosis and the irregularity in severity and distribution of the lesions, favours a post-natal and not a congenital or developmental origin of the bronchial abnormality.

We submit that the condition of unilateral transradiancy arises in most cases from infective damage to the bronchi and bronchioli in childhood and that hypoplasia and emphysema result from this damage.

A history of infection, often of a severe chest illness in childhood, is usually given, and is probably the cause of the bronchial and bronchiolar lesions. In many cases the history is elicited only on direct questioning since for the patient nothing seems to connect the two, in contrast to bronchiectasis when the cough and sputum commonly follow a childhood illness and are thus linked in his mind. Nor is there in most cases evidence as to whether the infecting organism is viral or bacterial, though in some the tubercle bacillus seems to have been responsible. Case 9 (see page 232) showed unilateral transradiancy in radiographs taken some months after recovery from childhood tuberculosis although earlier films had shown that the lung was normal.

A further case, that of a girl aged 12, illustrates the damage that may result from childhood tuberculosis. A resection specimen of the right lower lobe showed bronchiolar damage some months after radiographic clearing of a consolidation associated with tuberculosis. The child was seen because of contact with pulmonary tuberculosis. At first sight the resected lobe appeared normal, although the air spaces were rather coarse and irregular, but sections showed a peribronchiolar fibrosis with bronchiolar obliteration and distortion as well as some emphysema. The damage was widespread throughout the lobe and was not obvious on naked-eye examination of the lung nor apparent on the radiograph. It is probable that the growth of such a lobe would be retarded and, while ultimately smaller than normal, it might yet be more transradiant.

The absence of calcified glands in the radiograph cannot exclude tuberculosis as the cause. None was seen in these two patients, and Davies (1961) has shown that enlarged glands in primary tuberculosis do not necessarily heal with calcification.
It is only in its extent that total unilateral transradiancy is distinguishable from limited transradiancy of a lobe with similar clinical, radiographic, and pathological features, a view held by Belcher et al. (1959). The same can be said of transradiancy of a segment. When the change affects the whole lung, the characteristic picture is seen of a small right or left pulmonary artery ; when a lobe or part of it is affected, only the lobar artery is small. Bronchitis and bronchiolitis deformans and obliterans have been found by us in cases of lobar and segmental transradiancy to be the basic pathological change. Furthermore, where collapse of one lobe is associated with bronchiolitis obliterans in an adjacent one, the latter is more transradiant than would be expected solely as the result of compensatory increase in volume (see Fig. 10).

The evidence presented here suggests, contrary to Macleod's conclusion, that there is no distinction between $(a)$ unilateral transradiancy and transradiancy of a lobe or segment and $(b)$ tuberculosis and any other agent as the cause.

Hypoplasia of Pulmonary Tissue and Pulo MONARY ARTERY.-Infection in childhood occure when the lung is small and there is the expectanco of a long period of growth ahead. Mature growt is a work hypertrophy and the work of the bronchial tree is its alternate increase and reduction in calibre and length many times a minute during natural breathing. If there is less ventilation on the transradiant side, the lung does less work and may not grow as much as the normal lung. The main bronchus may be normal or it may be hypoplastic with a reduction in the thickness of its wall (Dornhorst et al., 1957) and an increased compressibility resulting from hypoplasia in the cartilage plates, these being either thinner than is normal or structurally immature.

The diameter of the pulmonary artery in the plain radiograph, tomogram, and angiogram was less than that of the artery on the normal side, but in the specimen, although smaller than normal, it was found to be larger than in the angiogram. Similarly, while there was some narrowing of the segmental arteries, the number of filled, fine, $\mathfrak{N}$ peripheral vessels in the injected specimen, although reduced, was still more than would be expected from the angiogram.

Probably no single factor explains the final $\stackrel{\mathcal{Q}}{+}$ haemodynamic state of the lung. It may be that 0 factors that were important during the first incident of damage are different from those that operate to maintain it. It has been shown that 
acute anoxia causes vasospasm (Fritts and Cournand, 1959) which, if it involved both lungs, would produce pulmonary hypertension but, involving only a local area, will cause deflection of flow, in this case from the whole of one lung to the other side. This vasospasm operates in an acute incident, but there is no evidence that it is responsible for maintaining the condition, since there is no evidence of hypertrophy of the media of the branches of the pulmonary artery.

The reduced ventilation which results from the bronchiolar damage will persist when the acute inflammation subsides and may play a part in prolonging a reduced flow. Cournand, Bryan, and Richards (1935), from a series of experiments on the effect of collapse on circulation, concluded that it was the depth of ventilation rather than the degree of collapse that affected the minute volume of blood-flow through the lung. This suggests that the pumping action of respiration contributes to the pulmonary circulation. Recent work (Riley, 1959) indicates that although deep inspiration may increase minute volume of bloodflow to the lung as a whole, the size of the capillary bed is reduced during the inspiratory phase. This suggests that the lung in which air is trapped, i.e., one relatively hyperinflated, offers mechanical resistance to flow through its capillaries, a further factor in cases of unilateral transradiancy which may contribute to atrophy of the capillary bed.

EMPHYSEMA.-In the three lungs examined the size of the alveoli was abnormally large, that is, they were emphysematous. In most areas the lung architecture was intact and the emphysema was of the distension, rather than the destruction, type (Reid and Simon, 1959).

In spite of the increase in volume of individual alveoli the lung volume was small, pointing to a true hypoplasia. Since the development of the thoracic cage is not retarded, the volume to be filled by the lung increases normally, whereas because of disease there is no normal increase in the number and substance of alveoli, those that there are becoming increasingly distended, whether initially emphysematous or not. The air trapping and reduction of capillary flow are factors which may increase the final alveolar size although their contribution is difficult to assess.

\section{SUMMARY}

Bronchograms of 12 cases of unilateral transradiancy are reviewed. In all of these and in bronchograms of previously published cases there was failure of normal conduction of the contrast medium and, in many, irregular tapering endings or dilatations, indicating organic occlusions.

In three cases the lung was resected and the specimens showed organic obliteration or distortion of many bronchi and bronchioli, hypoplasia of the lung and pulmonary arteries, and emphysema.

We believe that the condition is the result of infective damage to the airways in childhood, to which the small artery and hypoplasia of the lung are secondary.

Resection material, which shows that the distribution of transradiancy is not a critical factor and that similar pathological changes may affect only one or two lobes, is also presented.

Cases are described in which tuberculosis may have been the infection that caused the bronchiolar damage.

The authors wish to thank the colleagues whose patients are described here: Mr. J. R. Belcher, Dr. J. Smart, and Dr. G. Hinson for the pathological specimens of cases 1,2 , and 3 ; Mr. Dilwyn Thomas and Dr. R. Seal for resection material from the case of childhood tuberculosis; and Dr. F. H. Young and Dr. R. Bignall for the details of Case 9. For the illustrations we are grateful to Mr. A. Curd, Photographic Department, Institute of Diseases of the Chest, Brompton Hospital, and to Mr. N. K. Harrison, St. Bartholomew's Hospital.

\section{REFERENCE 3}

Areechon, W., and Reid, L. (1962). Brit. med. J., in press.

Belcher, J. R., and Pattinson, J. N. (1957). J. thorac. Surg., 34, 357. - Capel, L., Pattinson, J. N., and Smart, J. (1959). Brit. J. Dis. Chest, 53, 253.

Cournand, A., Bryan, N. A., and Richards, D. W. (1935). J. clin. Invest., 14, 181.

Darke, C. S., Chrispin, A. R., and Snowden, B. S. (1960). Thorax, $15,74$.

Davies, P. D. B. (1961). The Natural History of Tuberculosis Children. Tubercle (Lond.), 42, Suppl.

Dornhorst, A. C., Heaf, P. J., and Semple, S. J. G. (1957). Lancet. $2,873$.

Dyson, N. A., Hugh-Jones, P., Newbery, G. R., Sinclair, J. D., and West, J. B. (1960). Brit. med. J., 1, 231.

Fouché, R. F., Spears, J. R., and Ogilvie, C. (1960). Ibid., 1, 1312, Francis, H. B. (1961). Amer. J. Roentgenol., 85, 253.

Fritts, H. W., and Cournand, A. (1959). In Pulmonary Circulation, p. 62, edited by W. R. Adams and I. Vieth. Grune and Stratton, New York.

Katz, I., and Wagner, S. (1959). Radiology, 73, 362.

Leahy, D. J. (1961). Brit. J. Dis. Chest, 55, 72.

Macleod, W. M. (1954). Thorax, 9, 147.

Margolin, H. N., Rosenberg, L. S., Felson, B., and Baum, G. (1959). Amer. J. Roentgenol., 82, 63.

Reid, L. (1960). Thorax, 15, 132.

— and Simon, G. (1958). Ibid., 13, 103.

- - (1959). Brit. J. Radiol., 32, 291.

Riley, R. L. (1959). In Pulmonary Circulation, p. 147, edited by W. Adams and I. Veith. Grune and Stratton, New York.

Rivett, G. C. (1960). J. roy. Army med. Cps, 106, 151.

Swyer, P. R., and James, G. C. W. (1953). Thorax, 8, 133. 